\title{
Projets de paysage
}

Revue scientifique sur la conception et l'aménagement de l'espace

\section{$7 \mid 2012$}

Réédition d'articles du séminaire «Étapes de recherches en paysage » 2000-2006

\section{Présentation de la rubrique «Actualités/vie scientifique »}

\section{Chiara Santini}

\section{OpenEdition}

\section{Journals}

Édition électronique

URL : https://journals.openedition.org/paysage/17119

DOI : 10.4000/paysage.17119

ISSN : 1969-6124

Éditeur :

École nationale supérieure du paysage de Versailles-Marseille, Institut national des sciences appliquées Centre Val de Loire - École de la nature et du paysage, École nationale supérieure d'architecture et de paysage de Bordeaux, École nationale supérieure d'architecture et de paysage de Lille, Agrocampus Angers

\section{Référence électronique}

Chiara Santini, «Présentation de la rubrique «Actualités/vie scientifique » », Projets de paysage [En ligne], 7 | 2012, mis en ligne le 04 janvier 2012, consulté le 08 mai 2021. URL : http:// journals.openedition.org/paysage/17119; DOI : https://doi.org/10.4000/paysage.17119

Ce document a été généré automatiquement le 8 mai 2021.

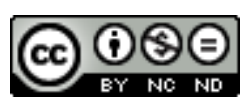

La revue Projets de paysage est mise à disposition selon les termes de la Licence Creative Commons Attribution - Pas d'Utilisation Commerciale - Pas de Modification 4.0 International. 


\section{Présentation de la rubrique "Actualités/vie scientifique »}

Chiara Santini 
1 Cette rubrique propose des textes différents de par leur typologie et leur thème qui visent à représenter les diverses approches possibles de la recherche sur le paysage et les jardins. Il s'agit également de présenter aux lecteurs une sélection de colloques et d'initiatives scientifiques.

2 Trois des contributions ici présentées visent à questionner l'identité et la construction du paysage français à différentes échelles : le territoire national, la capitale, les jardins du XVIII ${ }^{\mathrm{e}}$ siècle.

3 Pierre Donadieu présente le dernier ouvrage de Jean-Christophe Bailly qui propose une géographie des émotions et des représentations de la France issue d'un voyage au travers de quelques-uns de ses lieux les plus emblématiques.

4 Le dernier ouvrage de Pierre Pinon, analysé par Chiara Santini, retrace une histoire originelle de la capitale. Au travers des différents épisodes de destruction et de réaménagement dont la ville de Paris a été le théâtre à partir de l'époque moderne, Pinon met en lumière comment ce parcours de soustraction et d'effacement du patrimoine bâti fait partie intégrante de l'identité de la ville.

5 Le catalogue de l'exposition sur les jardins romantiques en France, qui a récemment eu lieu au Musée de la vie Romantique, aborde enfin une période longtemps négligée par les historiens de jardins et qui a joué un rôle important dans la mise en place d'un nouvel art de vivre la nature et dans le développement des professions liées à l'aménagement de l'espace.

6 Pour finir, Roland Vidal présente les objectifs et les contenus du colloque international "Construire l'équité territoriale en Tunisie ». Organisé à Tunis en novembre dernier, il a rassemblé une cinquantaine d'intervenants autour d'un débat concernant les attentes sociétales du pays en termes de paysage et d'aménagement du territoire au lendemain de la révolution tunisienne.

\section{AUTEUR}

\section{CHIARA SANTINI}

Historienne des jardins et des paysages et ingénieur de recherche à l'École nationale supérieure du paysage de Versailles-Marseille (ENSP).

c.santini[at]ecole-paysage[dot]fr 